\title{
Universal health care coverage: healthcare financing and access to health care services in Kenya
}

\author{
Phidiliah Rose Mwaambi* \\ Health systems strengthening specialist, Kenya
}

\begin{abstract}
Statement of the problem: A regressive system implies that rising income is matched with a falling fraction of income being paid to the health-care system. The constant utilization of out of pocket fees to finance health care is a constant barrier to health care access resulting in the impoverishment of households. Therefore allotment in financial contributions towards health care is a key component of modern day approaches to health system assessments (Murray and Evans 2003). Kenya is a low-income country on the East Coast of Africa. In Kenya, changes to health-care financing systems are being implemented to provide equitable access to health care with the aim of attaining universal healthcare coverage. Health care in Kenya is financed from three main sources: Out of pocket expenditure (households), government expenditure and donors.
\end{abstract}

Methodological and theory orientation: According to the Kakwani index-vertical measure of healthcare financing, Kenya seems regressive due to the high percentage of Out Of Pocket payments which is the most common method of accessing healthcare services (OOP). Currently, the total amount of the GDP allocated to the Ministry of health stands at $7 \%$ far from the commitment of $15 \%$ as part of the Bamako initiative. Recent health-care financing reforms have been characterized by a move away from OOP payments towards universal access to health care with financing through the National Health Insurance Fund. NHIF is Kenya's equivalent of a social health insurance fund where all employees in formal employment as well as volunteer members (in informal employment), make contributions to the fund (National Hospital Insurance Fund 2011) which has since increased its benefit package from inpatient services to include outpatient services.

Conclusion \& significance: The progress towards universal access to health care through NHIF has been met with significant challenges i.e perceived lack of good governance and lack of capacity among other reasons. Policy towards correcting this inequitable state of affairs needs to concentrate on the reduction of dependence of OOP payments and increasing the dependence on more progressive forms of health-care payments.

\section{Background}

Universal healthcare coverage (UHC) lies within the category of good health and well-being which is the third sustainable development goals (SDG3) that emphasizes on improving access to quality health services for all persons worldwide, protecting them from financial catastrophes and impoverishing health care costs. In the recent years, UHC has become a worldwide high priority policy agenda. The design of the healthcare financing system has implications in the access to health care services. This covers the five dimensions of accessing healthcare while ensuring quality and sustainable services based on need and not the ability to pay. In the Low and Middle Income Countries (LMIC), healthcare financing is predominantly done through contributory (social health insurance) and non-contributory mechanisms (Government revenues \& donors). Countries such as Kenya wherein lies the escalating costs of healthcare, mandatory prepayment for services are preferred because they have potential to generate high revenue, promote risk and income cross-subsidization thus minimizing financial barriers to accessing healthcare. In Kenya proposals have been made to register residences and income of those in the formal \& informal sector; with co-funding between the National and county governments; matching employer-employee contributions; cross subsidization of health services costs between Counties and also supporting the role of private healthcare providers. According to the kakwani index- vertical measure of healthcare financing, Kenya seems regressive due to the high percentage of Out Of Pocket (OOP) payments which is the most common method of accessing healthcare services. Health insurance coverage is low, with about $17.1 \%$ of households are reported to be in some form of prepayment health schemes. There is a need to strengthen accountability mechanisms; lower administrative costs incurred with health insurance in Kenya as well as tightening the regulatory framework for both public and private insurers.

National allocation to Kenya's 47 counties is based on a resource allocation formula that takes seven factors into account, including population, poverty, land share, and others. County allocations are given as block grants and counties determine the share to be allocated to health. County governments also collect some of their own revenue which are included as part of the county budgets before allocation to different sectors. In FY 2014/15, 38 of the 47 counties allocated at least $15 \%$ of their budget to health.

The National Hospital Insurance Fund (NHIF), is the governmental insurance scheme supported by the government which covers 4.5 million Kenyans $11 \%$ of the population while the private insurers cover a $4 \%$ of the population. Therefore this shows the larger population in Kenya that relies heavily in the governmental healthcare insurance scheme - NHIF. In the rural regions, community based insurance scheme exist. It is mandatory for all formal sector employees (public and private) and voluntary for those in the informal sector $[1,2]$.

Correspondence to: Phidiliah Rose Mwaambi, Health systems strengthening specialist, Kenya, E-mail: fidimwawasi@gmail.com

Received: December 04, 2017; Accepted: December 27, 2017; Published: December 29, 2017 


\section{Methodology}

Kakwani index (also Kakwani Progressivity Index): Defined as twice the area between the concentration curve for a payment (for taxes or health care etc.) and the concentration curve for income (or other measure of ability to pay). The index's value lies between -2 and 1 . A negative index regressively suggests (a lower proportion of income is paid out towards the payment as income increases) and a positive index suggests progressivity (a higher proportion of income is paid out towards the payment as income increases.

The Kakwani indices for the sources of health-care payments are summarized in Table 1.

Overall, the Kenyan health-care financing system is regressive with a negative Kakwani index regardless of assumption scenario used.

It is likely that the regressive nature of OOP payments is the chief contributor to this since all other payments are proportional. Wealthy Kenyans may have alternative sources of financing their health care and this may mean they do not have to resort to OOP payments as often as the poor.

High level of OOP payments increase the burden of care by households; are inequitable, inefficient and a barrier to access by the poor; high share of off-budget donor funding undermines strategic prioritization, it is disease focused, does not support health system strengthening and has potential contingent liabilities on the government when donor funds decline. Under the current devolved system of government, donor funding is likely to be more fragmented unless there is stewardship from county and National governments to ensure that donors support is aligned to local priorities; heavy reliance on OOP payments and donor funding undermines financial risk and income cross-subsidization, which are critical for the country's progress towards universal health coverage $[3,4]$.

\section{Discussion}

The Ministry of Health has the mandate with provision of social health insurance in order to protect the poor and vulnerable from

Table 1. Kakwani indices for the sources of health-care financing

\begin{tabular}{|c|c|c|c|c|c|}
\hline & Direct taxes & $\begin{array}{c}\text { Indirect } \\
\text { taxes }\end{array}$ & OOP & NHIF & $\begin{array}{c}\text { Private } \\
\text { insurance }\end{array}$ \\
\hline $\begin{array}{c}\text { Kakwani } \\
\text { index }\end{array}$ & 0.21 & -0.05 & -0.31 & -0.09 & 0.25 \\
\hline $\begin{array}{c}\text { (robust } \\
\text { standard } \\
\text { error) }\end{array}$ & 0.1235 & 0.0383 & 0.1289 & 0.0745 & 0.1990 \\
\hline $\begin{array}{c}P \text { value } \\
\text { 95\% } \\
\text { confidence } \\
\text { interval }\end{array}$ & -0.04 to 0.45 & -0.12 to 0.03 & -0.56 to -0.06 & -0.24 to 0.06 & -0.14 to 0.64 \\
\hline
\end{tabular}

Table 2. Kakwani indices for the overall financing system under various assumption scenarios

\begin{tabular}{|c|c|c|c|c|}
\hline \multirow{2}{*}{ Finance source } & Kakwani index & \multicolumn{3}{|c|}{ Macroweights } \\
\cline { 3 - 5 } & for source & Scenario 1 & Scenario 2 & Scenario 3 \\
\hline Direct tax & 0.21 & 0.17 & 0.18 & 0.10 \\
\hline Indirect tax & -0.05 & 0.22 & 0.22 & 0.13 \\
\hline NHIF & -0.09 & 0.06 & 0.06 & 0.07 \\
\hline OOP payments & -0.31 & 0.47 & 0.47 & 0.59 \\
\hline $\begin{array}{c}\text { Private } \\
\text { insurance }\end{array}$ & 0.25 & 0.08 & 0.08 & 0.11 \\
\hline $\begin{array}{c}\text { Kakwani Index for health-care } \\
\text { financing system }\end{array}$ & -0.10 & -0.10 & -0.15 \\
\hline
\end{tabular}

incurring catastrophic expenditure, which may further push them into poverty. Empirical evidence shows that preventive public health interventions are more cost effective than curative care. An efficient health system would allocate a significant share of funds to primary care due to widespread coverage of public primary health facilities and equity considerations, while maintaining lower but sufficient transfers to the national referral hospitals, as they are important for offering specialized care. However, in Kenya, about two thirds of the transfers are mainly to the two-referral hospitals: Kenyatta National Hospital and Moi Teaching and Referral Hospital.

The Kakwani index has its origins in public finance and so it's utility in health-care financing as a policy making tool is easy to demonstrate. In reference to the Kakwani index, for example, if the NHIF is to become the predominant source of health-care financing, then it implies that the contribution scale may need adjustment to make it more progressive.

In Kenya, the insurance market is small and employers pay some of private insurance premiums for their employees (Ministry of Medical Services \& Ministry of Public Health and Sanitation 2009a).

Overall progressivity of the health-care system is a function of the progressivity (or lack of it) of the individual sources of health-care financing. Given that only a small proportion of the Kenyan work force is in formal employment, the progressivity index for NHIF contributions may not adequately describe the actual distribution of burden of payment for the financing of health care in Kenya.

As a result of the high population, the Kenyan government has tried to provide equity in the health care system so as to effectively alleviate human suffering and improve life-styles of her citizens. The Kenyan medical system is marred by many factors that render accessibility and delivery of health care difficult. These factors include poor governance, overreliance on donor funds, traditional and cultural beliefs of the citizens, lack of efficient infrastructure, massive poverty and illiteracy therefore making it difficult for its citizens to access healthcare easily.

Measurement of access to healthcare is in terms of affordability, approachability and suitability of services and not just mere adequacy in supply of health facilities [5]. Accessibility is the ability for everyone, regardless of disability, social status, economic income or special needs among other classification, to admittance, use and benefit from everything within their health environment. Healthcare services are context specific to as many people as possible while taking to consideration the disease trends to the degree [6].

There are several well- written documents that lay emphasis on the importance of addressing barriers in accessing health and healthcare services yet little is done to improve the situation. This may be due to the different definitions, approaches and policies governing the healthcare system in Kenya. A common framework would be therefore suitable to facilitate the exchange of knowledge and expertise in order to improve healthcare and eliminate vulnerability in midst of accessing healthcare.

In public health and in relation to health care, vulnerability is defined as the stage at which an individual's health is predisposed to harm and risks. Vulnerability can be a cause of many factors such as the lack of access to health care and the reasons for it without the adequate self-protection or the individual's control. This renders the individual helpless and thereby undermining his/her wellbeing $[7,8]$. 


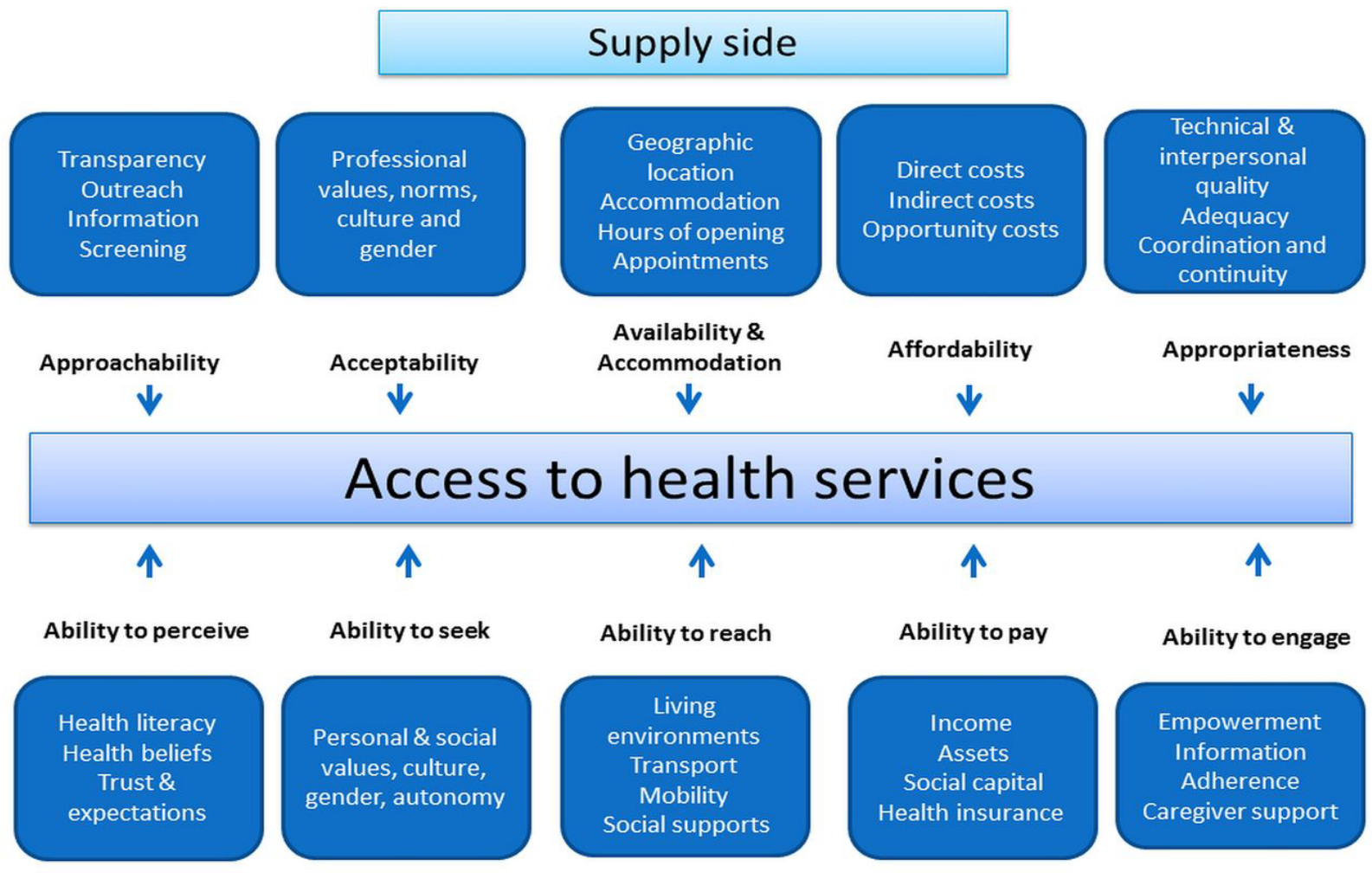

Figure 1. Framework for the study of access.

\section{Conclusion}

According to the kakwani index, the payments for healthcare are seen to be regressive in nature. The nature of out of pocket nature has regressively outweighed the proportional nature of other sources of payment. This has seen very minimal if not negligible different in protection against financial catastrophe by the public especially those living below the dollar. Thus the national government has to review the policy towards correcting this inequitable state of affairs to concentrate on the reduction of dependence of OOP payments and increasing the dependence on more progressive forms of health-care payments. By dedicating $15 \%$ of the national budget towards healthcare, there will be an uplift in the healthcare system enough to realize the Universal Healthcare Coverage as per the Abuja declaration of 2001 to which Kenya is a signatory. Better healthcare can be attained if accountability in the expenditure of funds used to facilitate the access to all Kenyans despite their purchasing power by utilizing the framework of access and bi-annual and annual evaluation of progressivity in service provision within the healthcare system.

Overall, reduction of reliance on out-of-pocket payments and move towards contributory financing mechanisms; increase preventive primary health care expenditure; and harmonize donor support for the sector. Devolution also provides a unique opportunity to address longstanding inefficiencies as well as inequities.

\section{References}

1. Chuma J, Okungu V (2011) Viewing the Kenyan health system through an equity lens: implications for universal coverage. Int J Equity Health 10: 22. [Crossref]

2. Munguti R (2010) New hospital fund rates blocked, Daily Nation.

3. Murray CJL, Evans D (2003) Health Systems Performance Assessment: Debates, Methods and Empiricism. Geneva World Health Organization.

4. Wamai R (2009b) The Kenya Health System — analysis of the situation and enduring challenges. Japan Medical Association 52: 134-40.

5. Gulliford M (2017) Access to primary care and public health. Lancet Public Health 2 e532-532e533. [Crossref]

6. Henry SL, Shadi AZ, Judy B (2014) "The Role of Accessibility in a Universal Web." Proceedings of the 11th Web for All Conference on - W4A '14, Seoul, Republic of Korea, April 7-9.

7. Maina T, Kirigia D (2015) Annual Evaluation of the Abolition of User Fees at Primary Healthcare Facilities in Kenya. Washington, DC: Futures Group, Health Policy Project.

8. Elkana (2012) "Healthcare financing reforms in Kenya". Stakeholders meeting on healthcare financing Kenya. 